\title{
Subcutaneous injection of inhaled anesthetics produces cutaneous analgesia
}

\author{
[L'injection sous-cutanée d'agents anesthésiques volatils génère une \\ analgésie cutanée] \\ Chin C. Chu MD, ${ }^{*} \ddagger$ Su Z. Wu MD, ${ }^{*}$ Wan L. Su Ms, ${ }^{*}$ Ja P. Shieh MD MS, ${ }^{*}$ Cheng H. Kao MD, $\dagger$ \\ Shung T. Ho MD MS, $\$$ Jhi J. Wang MD PhD*
}

Purpose: Previous investigations suggest that inhaled anesthetics may produce cutaneous analgesia. The objective of this study was to evaluate whether inhaled anesthetics have a direct analgesic effect on skin.

Methods: We conducted subcutaneous injections of one of three inhaled anesthetics (halothane, isoflurane, and enflurane) or one of two local anesthetics (lidocaine and procaine) at various dosages in rats ( $n=6$ rats, for each dose of each drug). Subcutaneous injections of vehicles (saline or olive oil) were used as controls ( $n=6$ rats for each vehicle). We constructed concentration-response curves, wherein the concentrations of drugs tested in subcutaneous tissue fluid were estimated by calculation, and the cutaneous analgesic effects of drugs were evaluated by pinprick tests on skin.

Results: Like local anesthetics, subcutaneous injection of inhaled anesthetics produced concentration-dependent, cutaneous analgesia which attained maximum (complete cutaneous analgesia) at high concentration. This effect was reversible and localized in the area of injection. On the basis of $50 \%$ effective concentration, the ranking of potencies was lidocaine $>$ halothane $>$ isoflurane $>$ enflurane $>$ procaine $(P<0.05$ for all differences). Subcutaneous injections of vehicles did not produce cutaneous analgesia.

Conclusions: Like local anesthetics (lidocaine and procaine), subcutaneous injections of inhaled anesthetics (halothane, isoflurane, and enflurane) produced a concentration-dependent, cutaneous, analgesic effect at the site of injection. Inhaled anesthetics have a direct analgesic effect on skin.

CAN J ANESTH 2008 / 55: 5 / pp 290-294
Objectif: Des recherches précédentes suggèrent que les agents anesthésiques volatils peuvent provoquer une analgésie cutanée. L'objectif de cette étude était de déterminer si les agents anesthésiques volatils ont un effet analgésique direct sur la peau.

Méthode: Nous avons procédé à des injections sous-cutanées d'un de trois agents anesthésiques volatils (halothane, isoflurane et enflurane) ou d'un de deux agents anesthésiques locaux (lidocaïne et procaïne) à différentes doses chez des rats ( $n=6$ rats, pour chaque dose de chaque agent). Nous avons eu recours à des injections sous-cutanées de véhicules (solution salée ou huile d'olive) comme témoins ( $n=6$ rats pour chaque véhicule). Nous avons élaboré des courbes concentration-effet, dans lesquelles les concentrations des agents à l'étude dans le liquide tissulaire sous-cutané ont été estimées par calcul, et les effets analgésiques cutanés des agents évalués par des tests de piqûre d'aiguille sur la peau.

Résultats : Tout comme les agents anesthésiques locaux, l'injection sous-cutanée d'agents anesthésiques volatils a généré une analgésie cutanée dépendante de la concentration qui a atteint son maximum (une analgésie cutanée complète) à une concentration élevée. Cet effet était réversible et localisé uniquement à la zone d'injection. Sur la base d'une concentration efficace à $50 \%$, le classement des puissances était lidocaïne $>$ halothane $>$ isoflurane $>$ enflurane $>$ procaïne $(P<0,05$ pour chaque différence). Les injections sous-cutanées de véhicules n'ont pas produit d'analgésie cutanée.

Conclusion : Tout comme les agents anesthésiques locaux (lidocaïne et procaïne), les injections sous-cutanées d'agents anesthésiques volatils (halothane, isoflurane, et enflurane) ont produit un effet analgésique cutané dépendant de la concentration au site d'injection. Les agents anesthésiques volatils ont un effet analgésique direct sur la peau.

From the Departments of Anesthesiology, ${ }^{*}$ and Surgery, $†$ Chi-Mei Medical Center, Tainan; the Graduate Institute of Medical Sciences, $\ddagger$ National Defense Medical Center, Taipei; and the Department of Anesthesiology, $\mathbb{\$}$ Tri-Service General Hospital, Taipei, Taiwan. Address correspondence to: Dr. Jhi-Joung Wang, Department of Anesthesiology, Chi-Mei Medical Center, Tainan, Taiwan.

Phone: 886-6-2517844; Fax: 886-6-2832639; E-mail: 400002@mail.chimei.org.tw

This work was completed at the Chi-Mei Medical Center, Tainan, Taiwan.

The authors do not have a financial relationship with any pharmaceutical company. Accepted for publication December 17, 2007.

Revision accepted February 25, 2008. 
I NHALED anesthetics produce unconsciousness, amnesia, immobilization, analgesia, and suppression of the autonomic nervous system. ${ }^{1-3}$ Despite their ubiquitous use in clinical anesthesia, some of the mechanisms by which inhaled anesthetics produce clinical anesthesia remain unclear, e.g., analgesia. ${ }^{1-3}$ Most previous studies evaluating the mechanisms of inhaled anesthetics have focused on the central nervous system effects, whereas relatively little work has been done on peripheral nervous system responses. ${ }^{1-4}$ Interestingly, several inhaled anesthetics affect not only the central nervous system, but also the peripheral nervous system. ${ }^{4}$ More studies are needed to evaluate the possible mechanisms of these drugs on the peripheral nervous system.

In 1998, Fassoulaki et al..$^{5}$ evaluated whether isoflurane had a direct analgesic effect on the skin. Using a method of topical application, they observed that isoflurane, when applied to the forearm of healthy volunteers for $30 \mathrm{~min}$, decreased pain scores in response to local mechanical and electrical stimulation. ${ }^{5}$ They suggested that isoflurane might have a direct analgesic effect on skin. While this was a fascinating observation, in this study, topical application of isoflurane did not produce complete cutaneous analgesia. Furthermore, no other inhaled anesthetics were tested. Since the keratin layers of skin could retard drug transfer, topical application of a drug for only 30 min might be too short a time span for drug transfer. ${ }^{6}$ Consequently, a longer period of time for topical application, or a procedure to circumvent this obstacle, should be considered. We therefore undertook a laboratory investigation using subcutaneous injection of drugs in rats. The aim of the study was to evaluate whether inhaled anesthetics have a direct analgesic effect on skin. The cutaneous analgesic effects of three inhaled anesthetics (halothane, isoflurane, and enflurane) and two, local anesthetics (lidocaine and procaine) were tested. Two vehicles (saline and olive oil) were used as controls.

\section{Methods}

We purchased male, Sprague-Dawley rats from the National Yang-Ming Medical College, Taipei, Taiwan. The rats were housed in groups of three for at least one week, in a climate controlled room that was maintained at $21^{\circ} \mathrm{C}$ with a relative humidity of approximately $50 \%$. Lighting was on a 12 -hr light/dark cycle (light on at 6:00 AM) with food and water available, ad libitum, up to the time of testing. On the day of testing, the weights of all of the rats were in the range of 200 to $250 \mathrm{~g}$. All tests were performed in accordance with the recommendations and policies of the International Association for the Study of Pain. The protocol was approved by the animal investigation committee of the Chi-Mei Medical Center.

The rats were handled daily, for up to seven days before the experiments, to familiarize them with the behavioural investigator, the experimental environment, and the specific experimental procedures. This familiarization minimized contamination of the rats, due to stress during the experiments, and generally improved the experimental performance. ${ }^{7}$ The dorsal hair of the thoracolumbar region $\left(10 \times 10 \mathrm{~cm}^{2}\right)$ of each rat was shaved the day prior to the experiment. Since we intended to construct a concentration-response curve for each drug tested, we used a total of 252 rats $(n=$ 6 rats for each dose of each drug and for each vehicle). Six to eight doses were tested for each drug. Each rat received only one injection of one of the medications.

Halothane, isoflurane, and enflurane were purchased from the Halocarbon Laboratories (River Edge, NJ, USA), Ohmeda Caribe Inc. (Guayama, Puerto Rico) and Baxter Caribe Inc. (Guayama, Puerto Rico), respectively. Injectable olive oil, lidocaine hydrochloride, and procaine hydrochloride were purchased from the Sigma Chemical Co. (St Louis, MO, USA). All medications were freshly prepared for subcutaneous injections. Since halothane, isoflurane, and enflurane are lipophilic drugs and cannot dissolve in $0.9 \%$ saline, they were prepared in olive oil, as oil solutions. ${ }^{8}$ Lidocaine hydrochloride and procaine hydrochloride were prepared in $0.9 \%$ saline, as solutions. The concentrations of drugs (either inhaled anesthetics or local anesthetics) in vehicles (either olive oil or saline) were presented as a percent of the drug in the vehicle (volume/volume).

For the preparation of local anesthetic solutions, lidocaine hydrochloride and procaine hydrochloride were initially prepared in saline as $2 \%$ solutions (weight/weight), respectively, and then further diluted with saline (volume/volume) to the required concentrations. For the preparation of inhaled anesthetics (in olive oil), the following steps were conducted. At room temperature of $21 \pm 2^{\circ} \mathrm{C}$ and one atmospheric pressure, a calculated volume of olive oil was initially injected into a glass vial $(2.0 \mathrm{~mL}$ in volume). This vial was then sealed by a Teflon-lined plug to make it gastight. A calculated volume of inhaled anesthetic was then injected into the vial to make a final volume of $1 \mathrm{~mL}$. After shaking the vial by hand for ten seconds, the inhaled anesthetics were completely dissolved into the olive oil. A $0.6 \mathrm{~mL}$ of oil solution was then aspirated for subcutaneous injection. During this preparation, Hamilton syringes $(1 \mathrm{~mL}$ in volume, Hamilton Co., Reno, NV, USA) were used for the aspiration of the drug and/or the vehicle. 
Subcutaneous injection of drugs was performed according to a previously reported method. ${ }^{7}$ In brief, these procedures were performed in conscious and unanesthetized rats, using a $27-\mathrm{G}$ needle to inject subcutaneously into the dorsal surface of the thoracolumbar region. For consistency, all drugs were prepared and injected by one experienced investigator (Dr. $\mathrm{Chu}$ ). Another experienced investigator (Ms. Su), who was blinded to the injected drugs, performed behavioural evaluation of the cutaneous analgesia.

In order to construct the concentration-response curves, the concentrations of drugs in tissue fluid at the injection sites were evaluated. Since lidocaine and bupivacaine were prepared in saline, the concentrations of these drugs in tissue fluid at the injection sites were considered as the same as those injected. While halothane, isoflurane, and enflurane were prepared in oil, their concentrations in tissue fluid at the injection sites were estimated by calculation, i.e., dividing the concentration of inhaled anesthetics in vehicle (olive oil) by their partition coefficients (PCs) between olive oil and physiological fluid. ${ }^{8-10}$ The PCs of inhaled anesthetics between olive oil and physiological fluid were also obtained by calculation using previously reported data. ${ }^{8-10}$ For example, the PC of halothane, between olive oil and gas, was 197, and the PC of isoflurane, between physiological fluid and gas, was 0.75; therefore, the PC of isoflurane, between olive oil and physiological fluid, is $197 / 0.75=263 . .^{8-10}$ Using this method, the PCs of isoflurane and enflurane, between olive oil and physiological fluid, were found to be $90.8 / 0.75=165$ and $96.5 / 0.74=130$, respectively. ${ }^{8-10}$

A wheal, or circular elevation of the skin, with an approximate diameter of $2 \mathrm{~cm}$, occurred after subcutaneous injection and was immediately marked with ink. The effect of cutaneous analgesia was evaluated using a previously reported method which tested the cutaneous, trunci, muscle reflex. ${ }^{7}$ In brief, this reflex was characterized by a reflex movement of the skin over the back, in response to local, dorsal, cutaneous stimulation. ${ }^{7}$ A Von Frey filament (no. 14), to which the cut end of an 18-G needle was affixed, was used to produce a standardized nociceptive stimulus ( $10 \mathrm{~g})$. Six pin-pricks (at six different points within each wheal) with a frequency of $0.5-1 \mathrm{~Hz}$ were used at each testing. ${ }^{7}$ Response to pin-prick test was defined in terms of percentage of possible effect (\% PE), so that $100 \%$ PE (i.e., a complete absence of all six responses) was defined as the complete nociceptive block. The test was applied every five minutes for the first $30 \mathrm{~min}$ and then every ten to $15 \mathrm{~min}$ for an additional two to three hours or longer, until the cutaneous reflex

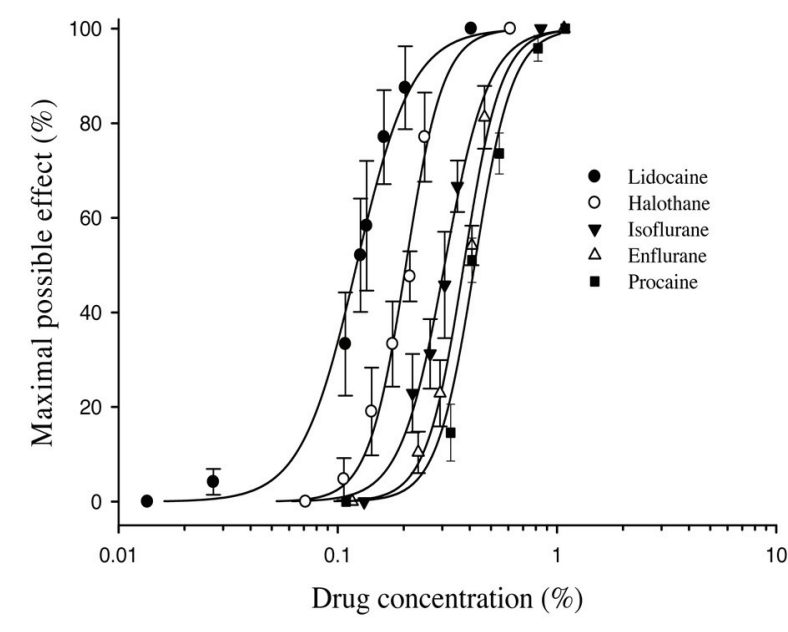

FIGURE The concentration-response curves of three inhaled anesthetics (halothane, isoflurane, and enflurane) and two local anesthetics (lidocaine and procaine) on cutaneous analgesia in rats ( $n=6$ rats at each testing point) after subcutaneous injection. Halothane, isoflurane, and enflurane were dissolved in olive oil, whereas lidocaine and procaine were dissolved in $0.9 \%$ saline. Values are mean \pm SEM.

completely recovered from the block. The maximal response of each dose of each drug (\% maximal possible effect) was chosen as the representative of each dose of each drug. In order to rule out the possibility that the systemic effects of injected drugs, after absorption, caused cutaneous analgesia, a pinprick test was performed on each rat at the contralateral, counterpart skin of the injected site. In order to rule out the possibility of cutaneous analgesia resulting from vehicle, two control groups $(n=6$ rats each) were used: one group received subcutaneous saline and the other group received subcutaneous olive oil.

In the concentration-response curves, the values were presented as mean \pm SEM. The concentrationresponse curves were fitted individually for each drug with the Hill equation, and $50 \%$ effective concentrations $\left(\mathrm{EC}_{50} \mathrm{~s}\right)$, with $95 \%$ confidence intervals $(95 \%$ CIs), were obtained after fitting. The $\mathrm{EC}_{50}$ was defined as the concentration of drug that caused a $50 \%$ block of the cutaneous, trunci, muscle reflex. ${ }^{11}$ The differences in potencies $\left(\mathrm{EC}_{50} \mathrm{~s}\right.$ with their $\left.95 \% \mathrm{CIs}\right)$ between drugs were evaluated by the $\mathrm{F}$ test, followed by the Student's $t$ test with Bonferroni correction. A P value $<0.05$ was considered significant. 
TABLE The $50 \%$ effective concentrations $\left(\mathrm{EC}_{50} \mathrm{~s}\right)$ of drugs with $95 \%$ confidence interval $(95 \% \mathrm{CI})$ on cutaneous analgesia in rats

\begin{tabular}{lll}
\hline Drugs & $E C_{50}(95 \% C I)$ & P-value \\
\hline Lidocaine & $0.13(0.12-0.14)$ & \\
Halothane & $0.18(0.17-0.20)$ & $<0.001$ \\
Isoflurane & $0.33(0.31-0.35)$ & $<0.001$ \\
Enflurane & $0.38(0.37-0.40)$ & 0.012 \\
Procaine & $0.44(0.42-0.46)$ & 0.006 \\
\hline
\end{tabular}

The $\mathrm{EC}_{50}(95 \% \mathrm{CI})$ of each drug (\%) was obtained from computer-derived curve fitting by SAS NLIN analysis of the concentration-response curve of each drug shown in the Figure. The ranking of potencies of drugs was lidocaine $>$ halothane $>$ isoflurane $>$ enflurane $>$ procaine, which was evaluated by the $\mathrm{F}$ test, followed by the Student's $t$ test with Bonferroni correction.

\section{Results}

Similar to the local anesthetics (lidocaine and procaine), the three inhaled anesthetics (halothane, isoflurane, and enflurane) produced concentrationdependent, cutaneous analgesia which attained maximum effect (100\% PE, complete nociceptive block) at high concentrations (Figure). Both the local anesthetics and the inhaled anesthetics produced reversible, cutaneous analgesia. All of the rats recovered completely within six hours after subcutaneous injection of the tested anesthetics. On the basis of $\mathrm{EC}_{50}$, the ranking of potencies was lidocaine $>$ halothane $>$ isoflurane $>$ enflurane $>$ procaine (Table). In the rats that were injected with either one of the local anesthetics or with one of the inhaled anesthetics, no cutaneous analgesia were found at the contralateral, counterpart skins of the injected sites. Also, no cutaneous analgesia was observed at the injected sites of the rats that were injected with saline or olive oil.

\section{Discussion}

Our results indicate that the inhaled anesthetics halothane, isoflurane and enflurane, have an analgesic effect on skin. On the basis of an $\mathrm{EC}_{50}$ ranking, the potencies of these inhaled anesthetics were between those of lidocaine and procaine.

Because these three inhaled anesthetics produced cutaneous analgesia through a local mechanism after subcutaneous injection, this mechanism might also play a role on the analgesic effect of inhaled anesthetics during general anesthesia. Further pharmacokinetic studies are warranted to evaluate the tissue concentrations of inhaled anesthetic during inhaled general anesthesia. Such studies would, however, be challenging due to technical difficulties.
We found that the three inhaled anesthetics produced concentration-dependent, cutaneous analgesia, similar to that of the local anesthetics. Local anesthetics are well-known to produce cutaneous analgesia through their $\mathrm{Na}^{+}$channel blocking activities on the peripheral nervous system. ${ }^{12,13}$ Inhaled anesthetics are also known to have $\mathrm{Na}^{+}$channel blocking activities, not only on the central nervous system, but also on the peripheral nervous system. ${ }^{14-16}$ Accordingly, it is possible that inhaled anesthetics may exert their cutaneous analgesic effect through similar $\mathrm{Na}^{+}$channel blocking activities on the cutaneous nervous system, although more studies are needed to confirm this speculation.

In this study, we did not attempt to detect the local tissue concentrations of inhaled anesthetics, because of the technical difficulties of such focused tissue sampling. Instead, we estimated the concentrations of inhaled anesthetics by calculation using the known PC values of these anesthetics between vehicle and tissue fluid. ${ }^{8-10}$ Our results indicate that the three inhaled anesthetics produced cutaneous analgesia under local tissue concentrations of $0.18-0.44 \%$ $\left(\mathrm{EC}_{50} \mathrm{~s}\right)$. Actually, in in vivo conditions, the true, local tissue concentrations of inhaled anesthetics may be lower than the above calculated values, and the concentrations required to produce cutaneous analgesia may be lower. This could be so, since our values were obtained by calculation using in vitro PCs values. ${ }^{8-10}$ Under in vitro conditions, the inhaled anesthetics were delivered from the donor site to the receiver site (tissue fluid) without subsequent dilution at the receiver site. ${ }^{8-10}$ However, under in vivo conditions, the inhaled anesthetics at the receiver site (tissue fluid) were subsequently absorbed into systemic circulation due to concentration gradients.

In this study, olive oil was used as a vehicle for inhaled anesthetics. Before this study, several solvents (e.g., intralipid, lecithin, sesame oil, peanut oil, cotton seed oil, olive oil, etc.) had been evaluated for their potential suitability as vehicles for inhaled anesthetics. Amongst these solvents, olive oil demonstrated the best solubility for inhaled anesthetics.

We conclude that, like local anesthetics (lidocaine and procaine), subcutaneous injection of the three inhaled anesthetics (halothane, isoflurane, and enflurane) produces a concentration-dependent, cutaneous analgesic effect at the sites of injection. Inhaled anesthetics have a direct, analgesic effect on skin.

\section{References \\ 1 Campagna JA, Miller KW, Forman SA. Mechanisms of actions of inhaled anesthetics. N Engl J Med 2003; 348: $2110-24$.}


2 Evers AS, Crowder CM. General anesthetics. In: Hardman JG, Limbird LE (Eds). Goodman \& Gilman's the Pharmacological Basis of Therapeutics, $10^{\text {th }} \mathrm{ed}$. NY: The McGraw-Hill Companies; 2001: 337-65.

3 Hemmings HC Jr, Akabas MH, Goldstein PA, Trudell $J R$, Orser BA, Harrison NL. Emerging molecular mechanisms of general anesthetic action. Trends Pharmacol Sci 2005; 26: 503-10.

4 Scholz A, Appel N, Vogel W. Two types of TTX-resistant and one TTX-sensitive $\mathrm{Na}+$ channel in rat dorsal root ganglion neurons and their blockade by halothane. Eur J Neurosci 1998; 10: 2547-56.

5 Fassoulaki A, Sarantopoulos C, Karabinis G, Derveniotis $C$. Skin application of isoflurane attenuates the responses to a mechanical and an electrical stimulation. Can J Anaesth 1998; 45: 1151-5.

6 Grond S, Radbruch L, Lehmann KA. Clinical pharmacokinetics of transdermal opioids: focus on transdermal fentanyl. Clin Pharmacokinet 2000; 38: 59-89.

7 Khan MA, Gerner P, Sudoh Y, Wang GK. Use of a charged lidocaine derivative, tonicaine, for prolonged infiltration anesthesia. Reg Anesth Pain Med 2002; 27 : 173-9.

8 Honemann CW, Washington J, Honemann MC, Nietgen GW, Durieux ME. Partition coefficients of volatile anesthetics in aqueous electrolyte solutions at various temperatures. Anesthesiology 1998; 89: 10325.

9 Firestone LL, Mille, JG, Mille, KW. Tables of physical and pharmacological properties of anesthetics. In: Roth SH, Miller KW (Eds). Molecular and Cellular Mechanisms of Anesthetics. NY: Plenum Medical Book Company; 1986: 455-70.

10 Renzi F, Waud BE. Partition coefficients of volatile anesthetics in Kreb' s solution. Anesthesiology 1977; 47: 62-3.

11 Minkin S, Kundhal K. Likelihood-based experimental design for estimation of ED50. Biometrics 1999; 55 : 1030-7.

12 Fozzard HA, Lee PJ, Lipkind GM. Mechanism of local anesthetic drug action on voltage-gated sodium channels. Curr Pharm Des 2005; 11: 2671-86.

13 Lipkind GM, Fozzard HA. Molecular modeling of local anesthetic drug binding by voltage-gated sodium channels. Mol Pharmacol 2005; 68: 1611-22.

14 Ouyang W, Hemmings HC Jr. Depression by isoflurane of the action potential and underlying voltage-gated ion currents in isolated rat neurohypophysial nerve terminals. J Pharmacol Exp Ther 2005; 312: 801-8.

15 Ouyang W, Wang G, Hemmings HC Jr. Isoflurane and propofol inhibit voltage-gated sodium channels in isolated rat neurohypophysial nerve terminals. Mol Pharmacol 2003; 64: 373-81.
16 Rehberg B, Xiao $\Upsilon H$, Duch DS. Central nervous system sodium channels are significantly suppressed at clinical concentrations of volatile anesthetics. Anesthesiology 1996; 84: 1223-33. 